\title{
Ground-roosting in domestic fowl (Gallus gallus domesticus) in The Gambia: the anticipation of night
}

\author{
J.P. Kent ${ }^{\mathrm{a} *}$, A.G. McElligott ${ }^{\mathrm{b}}$, H.V. Budgey ${ }^{\mathrm{a}}$ \\ ${ }^{a}$ Ballyrichard House, Arklow, Co. Wicklow, Ireland \\ ${ }^{\mathrm{b}}$ St. Joseph's Poultry Foundation, The Catholic Mission, Bwaim, Gambia
}

Received 3 April 1996; revised 1 October 1996; accepted 23 October 1996

\begin{abstract}
The ground-roosting behaviour of a semi-feral population of domestic hens with broods of chicks was measured in The Gambia, West Africa. Although neither day length nor time of sunset changed significantly over the duration of the study (January-March 1995), mean daily light intensity showed a significant increase. This resulted in an increasingly rapid decline in light intensity at dusk as the season progressed. Hens went to roost significantly later in the day, and at lower light levels, over the course of the season. The results support a model suggesting that the cue to start roosting is a certain light level, constant over the season, but the 'settling period' required means that the hens finally roost at later times and at lower light levels as the season progresses. (C) 1997 Elsevier Science B.V.
\end{abstract}

Keywords: Circadian rhythm; Domestic fowl; Ground-roosting; Photosensitivity

\section{Introduction}

A number of studies have examined interactions between the mother hen and her young chicks (e.g. Brückner, 1933; McBride et al., 1969; Workmann and Andrew, 1989; Kent, 1992). During the first days of the chicks' life the hen broods them for the night on the ground, at or near the old nest site, in what is called 'ground-roosting' behaviour (McBride et al., 1969). However, little

\footnotetext{
* Corresponding author.
}

is known about the environmental cues such as time of day, light intensity and temperature that are associated with this behaviour pattern. The role of light intensity and time in roosting behaviour has been widely studied in species such as starlings (Davis, 1955; Davis and Lussenhop, 1970), rooks (Swingland, 1976) and magpies (Reebs, 1986). Many organisms have free-running endogenous rhythms, but are entrained to $24 \mathrm{~h}$ by the cycle of day and night (Gwinner, 1975; Palmer, 1976; Hader and Tevini, 1987; Brady, 1979). Alternative mechanisms for synchronisa- 
tion have been suggested: an animal may 'measure' day or night length against circadian periodicity of $24 \mathrm{~h}$, or it may use a 'zeitgeber' or 'interval timer', started and stopped by sunrise and sunset (Brady, 1979). Changing light intensities during sunrise and sunset appear to be one of the most important factors for synchronisation (e.g. Morris, 1973; Bhatti and Morris, 1978a,b; Brady, 1982; Reebs, 1994), and it has been shown that in birds, the transparency of the skull is sufficient to allow intensities of around 10 lux to reach a photoreceptor in the cerebrum (Hader and Tevini, 1987). It is now generally accepted that photosensitivity (the threshold of an animal's sensitivity to light) is governed by circadian rhythm, but that photoperiodic reactions (the animal's behavioural response to light intensity, such as going to roost) are stimulated only when light coincides with photosensitive periods (Pittendrigh and Morris, 1964; Pittendrigh, 1972; Hader and Tevini, 1987). This theory, known as the 'coincidence model', explains why birds will only be stimulated to go to roost in the evening, even though the environmental conditions (such as light levels) acting as the cues to roosting may occur at other times of the day (Saunders, 1977; Applin and Cloudsley-Thompson, 1982; Brady, 1982). For example, Petherick and Waddington (1991) found that domestic hens were unable to entrain to a cue signalling dusk if it did not occur within the context of a diurnal rhythm. However, in many species, correlations of light intensity with arrival at the roost are not good (Swingland, 1976). In his study of roosting in starlings, Davis (1955) suggested that wide variation in arrival times at the roost may be at least partially explained by further observations earlier in the roosting sequence, when light intensity may play a stronger role. Davis and Lussenhop (1970) subsequently demonstrated that starlings' departure towards the roost was closely correlated with light intensity, but that as the roost is approached there is a weaker correlation with light levels. This study investigates the relationship between the time that broody hens settle for the night, light intensity and a range of other factors in The Gambia. The study site provides an opportunity to observe the behaviour of a semi-feral popula- tion of domestic fowl in an environment where light intensity changes with the seasons, though daylength remains relatively constant. Furthermore, light levels are free of such confounding and unpredictable factors as cloud cover during the study period. Thus, a detailed study of the role of light intensity and factors such as time, season and temperature on ground-roosting behaviour is possible.

\section{Methods}

\subsection{Study site and subjects}

The study was carried out in Bwiam, a village approximately $110 \mathrm{~km}$ east of Banjul and $14^{\circ} \mathrm{N}$ of the equator. The climate is sub-tropical, and observations were made during the dry season (January-March) of 1995. Because of The Gambia's equatorial latitude, daylength remains relatively constant throughout the year, although light intensity, temperature and rainfall vary with the seasons. Domestic hens of mixed European origin are maintained by individual households for egg and meat production in semi-feral conditions. The hens are productive all year round; they lay eggs, incubate, hatch and rear chicks in or near the family compound and are sometimes housed, while adult and juvenile fowl may also roost in trees. On hatching the hen broods her chicks for the night on or near the original nest site in what is termed 'ground-roosting' behaviour. Roosting on the ground also has the advantage of being more easily observed and measured than roosting in trees.

\subsection{Procedures and analyses}

Sixteen broody hens with young chicks were individually observed on three consecutive evenings from approximately $17.30 \mathrm{~h}$ until they settled for the night. The number and age of chicks was noted for each hen, and the measures taken on the three consecutive observation days were averaged for each hen. Final ground-roosting was defined as occurring when the hen settled in position for the night with all her chicks 


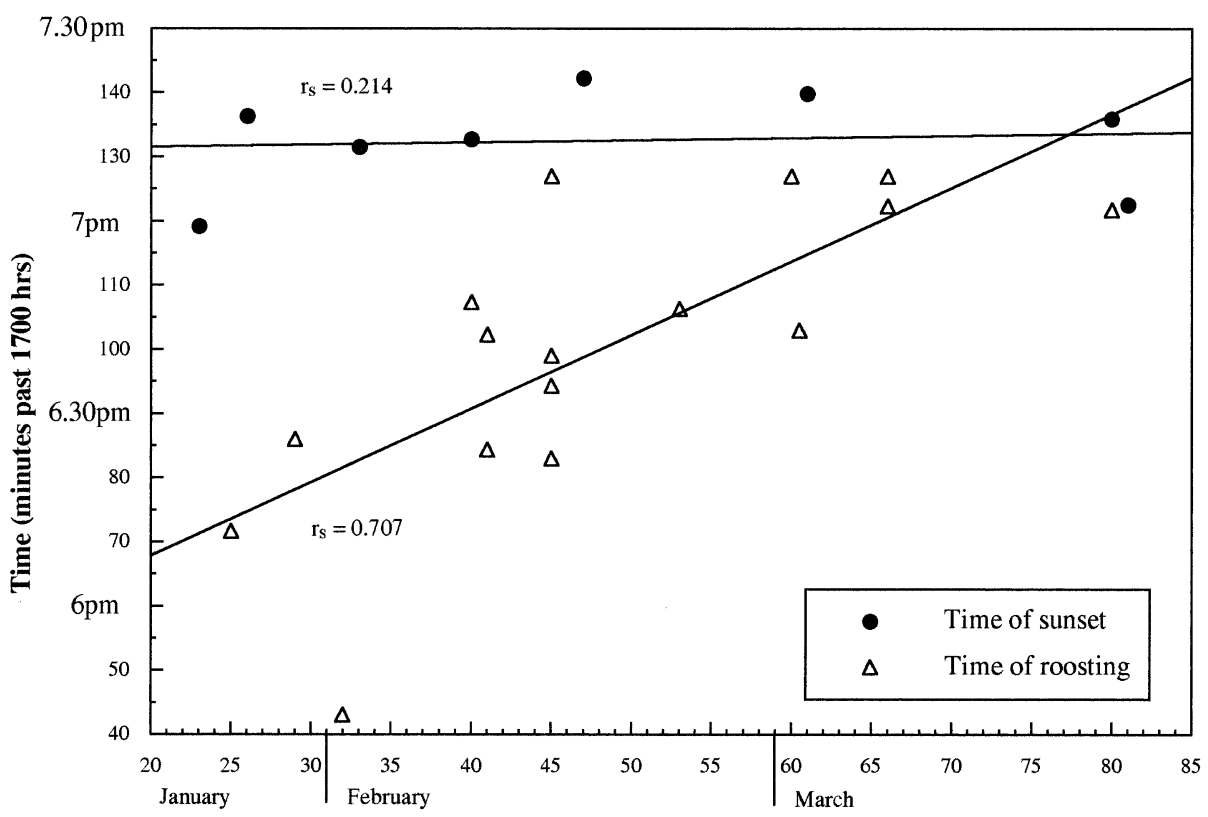

Date (1995 days)

Fig. 1. Changes in (i) time of sunset and (ii) time of ground roosting by hens. The vertical axis shows time in min past $17.00 \mathrm{~h}$; the horizontal axis shows date in days from 1 January 1995. There is no significant change in time of sunset over the season ( $P=0.2843)$, but time of roosting occurs significantly later as the season progresses $(P=0.0028)$. See text for details of statistical analysis.

brooded under her. The time and temperature at final ground-roosting were recorded, and light intensity (lux) was measured using an INS DX200 Digital Illumination meter (Edmund Scientific Company), pointed towards the zenith. Lux levels were also recorded at $18.15 \mathrm{~h}$, when changes in light intensity appeared to the human observer to decline most rapidly. Additional measures were taken between one and three times a week over the duration of the study to examine changes in light intensity over the day: lux measures were taken every hour on the hour from $07.00 \mathrm{~h}$ to $19.30 \mathrm{~h}$, and every $15 \mathrm{~min}$ for the first and last half hour each day in order to determine when sunrise and sunset occurred. Since it was not always possible to ascertain exactly when lux levels reached zero, the time that light intensity reached 100 lux was used to define sunrise and sunset.

Throughout this paper, the measurements used are defined as follows: '1995 date' indicates days past 1 January 1995; 'time of day' indicates min past $17.00 \mathrm{~h}$; 'light intensity' is measured in lux; and 'temperature' in degrees centigrade.

The data were analysed using the 'Statview', 'Minitab' and 'Microsoft Excel' packages for the Macintosh, in accordance with the procedures for multivariate regression analysis (Zar, 1984; Kleinbaum et al., 1988) and Spearman's rank correlation coefficient (Siegel, 1956). All measures of significance are two-tailed.

\section{Results}

The values of the main variables are as follows: time of sunrise (100 lux): range $=06 \mathrm{~h} 43 \mathrm{~min} 43$ $\mathrm{s}$ to $06 \mathrm{~h} 48 \min 01 \mathrm{~s}$, mean $=06 \mathrm{~h} 45 \min 46 \mathrm{~s}$; time of sunset (100 lux): range $=19 \mathrm{~h} 11 \min 41 \mathrm{~s}$ to $19 \mathrm{~h} 13 \min 34 \mathrm{~s}$, mean $=19 \mathrm{~h} 12 \min 29 \mathrm{~s}$; light intensity over the day: range $=0$ to 102600 lux; light intensity at roosting: range $=414.60$ to 


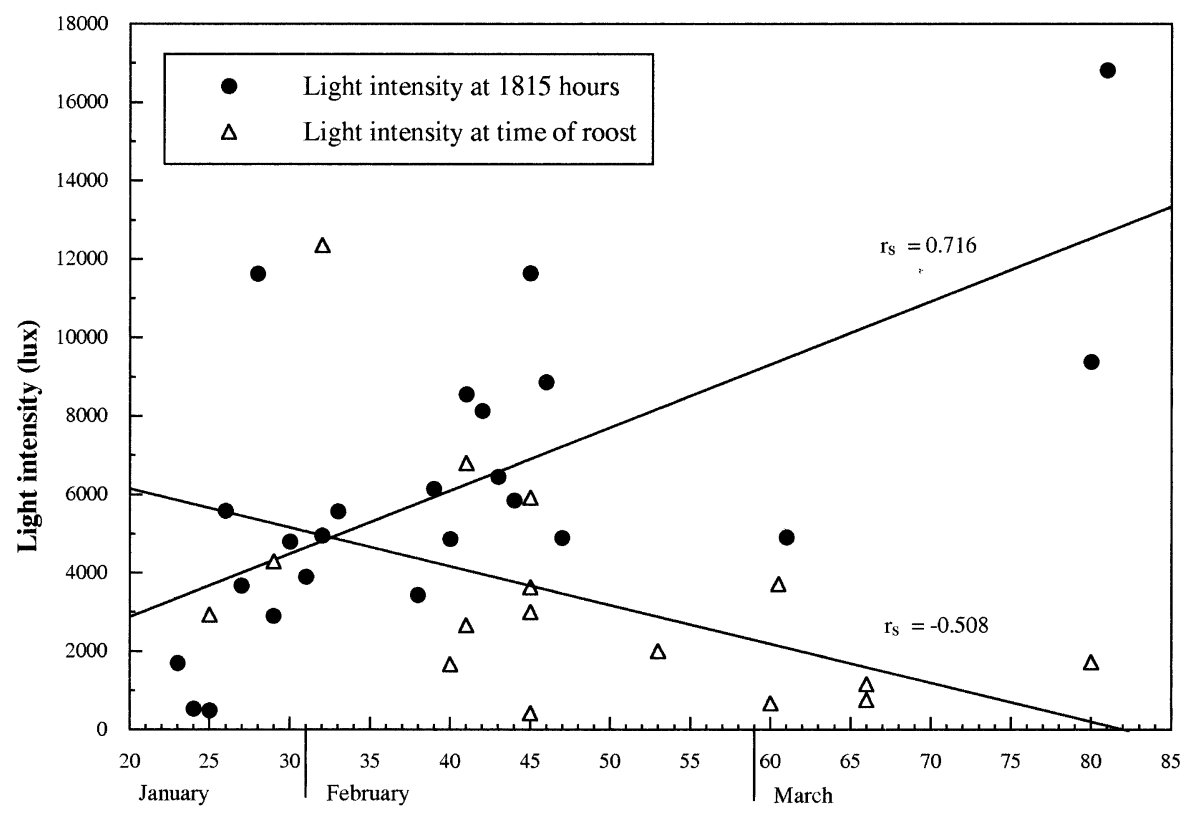

Date (1995 days)

Fig. 2. Changes in levels of light intensity (i) at $18.15 \mathrm{~h}$ and (ii) when hens finally roost for the night. The vertical axis shows light intensity in lux; the horizontal axis shows date in days from 1 January 1995. There is a significant increase in daily light intensity over the season $(P=0.0007)$, and a significant decline in light intensity at roosting as the season progresses $(P=0.0244)$. See text for details of statistical analysis.

12357.00 lux, mean $=3352.54$ lux; temperature at roosting: range $=28-32.25^{\circ} \mathrm{C}$, mean $=30.39^{\circ} \mathrm{C}$; brood size: range $=2.33-14$, mean $=6.69$; chick age: range $=1.5-9$ days, mean $=5.97$ days. Although neither the time of sunrise, nor the time of sunset, showed any significant variation over the study period (sunrise: $N=8, r_{\mathrm{s}}=-0.350, P=$ 0.1230 ; sunset: $\left.N=8, \quad r_{\mathrm{s}}=0.214, \quad P=0.2843\right)$, hens were going to roost significantly later, and therefore closer to sunset, as the season progressed ( $\left.N=16, r_{\mathrm{s}}=0.707, P=0.0028\right)$ (Fig. 1). Similarly, females went to roost at decreasing levels of light intensity over the season $(N=16$, $\left.r_{\mathrm{s}}=-0.508, P=0.0244\right)$, although mean light intensity throughout the day was in fact increasing over the same period (readings at $18.15 \mathrm{~h}: N=21$, $r_{\mathrm{s}}=0.716, P=0.0007$ ) (Fig. 2).

The relationship between time of day, light intensity and season indicates that the decline in light intensity in the evenings will occur increasingly rapidly as the days go by, as shown by the model depicted in Fig. 3. Figs. 1 and 2 show that both the time and the light intensity at which hens ground-roost is correlated with the time of year. Stepwise multiple regression analysis was used to

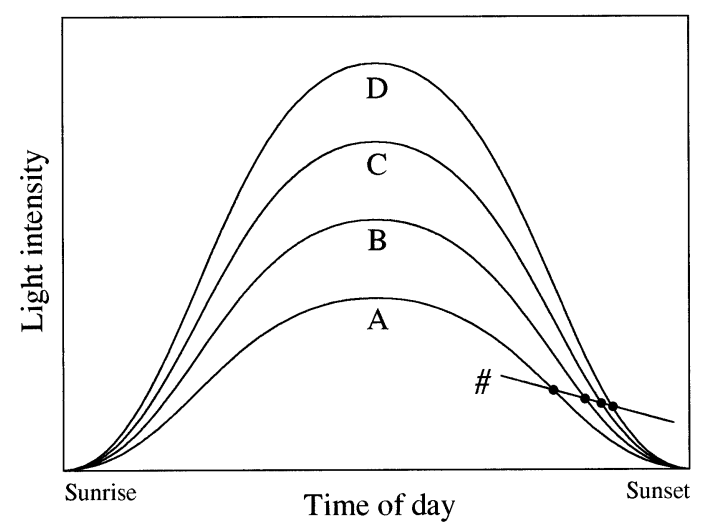

Fig. 3. Model showing changes in light intensity over the day from sunrise to sunset. The curved lines represent four different dates, from early season (A) to late season (D). The straight line \# illustrates that as the season progresses, hens go to roost later, and at a lower light intensity, each day. 
Table 1

Stepwise multiple regression analysis of a range of environmental and life history factors potentially involved in the ground roosting behaviour of chickens

\begin{tabular}{lllllll}
\hline Time & Date & Temperature & Brood size & Chick age & Intercept & Significance \\
\hline-156.846 & 82.965 & -236.678 & -109.877 & -63.601 & 23384.773 & $\mathrm{R}^{2}=0.878$ \\
$(2.050 \mathrm{E}-05)$ & $(0.041)$ & $(0.494)$ & $(0.504)$ & $(0.715)$ & $(0.062)$ & $(0.0003)$ \\
-159.946 & 86.513 & -207.694 & -85.070 & & 22097.889 & $\mathrm{R}^{2}=0.876$ \\
$(5.559 \mathrm{E}-06)$ & $(0.0241)$ & $(0.520)$ & $(0.553)$ & & $(0.0555)$ & $(5.920 \mathrm{E}-05)$ \\
-157.337 & 80.296 & -126.079 & & 19087.503 & $\mathrm{R}^{2}=0.872$ \\
$\mathbf{( 4 . 0 2 3 E}-\mathbf{0 6})$ & $\mathbf{( 0 . 0 2 4})$ & $\mathbf{( 0 . 6 5 6}$ & & $\mathbf{( 0 . 0 5 5 )}$ & $\mathbf{( 1 . 2 0 6 E}-\mathbf{0 5})$ \\
$\mathbf{- 1 5 2 . 6 4 5}$ & $\mathbf{7 6 . 3 4 0}$ & & & $\mathbf{1 4 9 7 6 . 3 3 3}$ & $\mathbf{R}^{\mathbf{2}}=\mathbf{0 . 8 7 0}$ \\
$(9.367 \mathrm{E}-07)$ & $(0.02)$ & & & $(1.080 \mathrm{E}-08)$ & $(1.741 \mathrm{E}-06)$ \\
-116.462 & & & & 15036.783 & $\mathrm{R}^{2}=0.805$ \\
$(1.623 \mathrm{E}-06)$ & & & $(9.276 \mathrm{E}-08)$ & $(2.494 \mathrm{E}-06)$ \\
Equation: light intensity at roosting $=(76.34 \times$ date $)-(152.65 \times$ time $)+14976.33$. & & \\
\hline
\end{tabular}

The best predictors of light intensity at roosting are time and date, and the regression model of best fit is shown by the equation at the bottom of the table.

Values are given as coefficients with, in parentheses, the probability $P$.

determine the relative contribution and error variance of a range of environmental and life history variables: (i) light intensity, (ii) time of day, (iii) date, (iv) temperature, (v) brood size and (vi) age of chicks. Table 1 shows that the last three partial correlates have negligible influence on groundroosting behaviour, and that light intensity at roosting can be predicted by the combined influence of time of day and date plus a constant of 14976.33 lux.

Examination of the daily crepuscular decline in light intensity shows that the value of 14976 lux occurs significantly later in the day as the season progresses $\left(N=8, r_{\mathrm{s}}=0.905, P=0.0167\right)$ (Fig. 4). It can be seen that this line $(y=1.017 x+9.632)$ is almost parallel with the line depicting the seasonal increase in the time that the hens finally groundroost $(y=1.146 x+44.912)$. A test of homogeneity of regression reveals that there is no significant difference between the slopes of the two lines $\left(\mathrm{F}_{1,20}=0.1327, P=0.7195\right)$. Over the observation period, therefore, there is a constant delay of 35 min $18 \mathrm{~s}$ from the time the light intensity reaches 14976 lux, until the hen finally goes to roost.

\section{Discussion}

Fig. 1 shows that although the time of sunset did not change significantly over the three month study period, hens were settling to brood their chicks later each day. It has often been suggested that a certain light intensity may be an important cue in determining roosting times (e.g. Davis, 1955; Davis and Lussenhop, 1970; Swingland, 1976; Reebs, 1986). In this study hens roosted at decreasing light levels as the season progressed (Fig. 2). Wood-Gush et al. (1978) found that the roosting of domestic fowl in Scotland with and without broods was closely associated with the time of sunrise and sunset, which varies with the season; however, since the time of sunrise and sunset in The Gambia did not change significantly over the period of study, there is no evidence to suggest that the birds are using an internal zeitgeiber to measure time and thus provide a cue for roosting.

Multiple regression analysis of a range of environmental and life history variables indicates that much of the variation in ground-roosting behaviour is associated with the effects of time of 


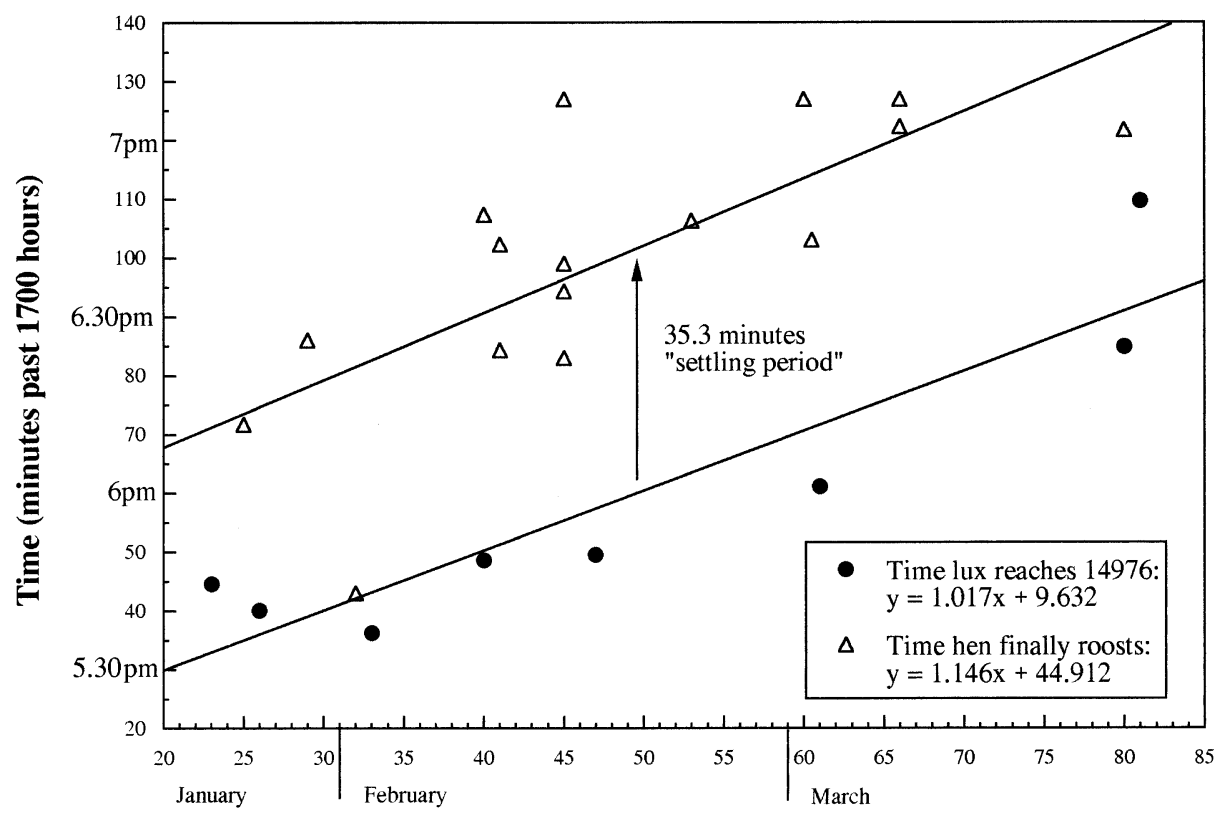

Date (1995 days)

Fig. 4. Changes in (i) time that light intensity drops to 14976 lux and (ii) time that hens go to roost, over a three month study period in The Gambia. The vertical axis shows time in $\min$ past $17.00 \mathrm{~h}$; the horizontal axis shows date in days from 1 January 1995. There is no significant difference between the slopes of the lines (test for homogeneity of regression: $\mathrm{F}_{1,20}=0.1327, P=0.7195$ ), and there is a constant time lag over the season of $35.3 \mathrm{~min}$ (the 'settling period') from the time when light intensity reaches 14976 lux until the hen finally settles to roost.

day and season, plus a constant of 14976 lux. Light intensity varies positively with the date, and negatively with time. We suggest that the data are consistent with a model in which the cue for starting ground-roosting in the evening occurs as the light intensity reaches a certain level, which remains constant over the season (shown by the line $\S$ in Fig. 5). Our data suggest that the value of $\S$ would be 14976 lux.

Given that the days are brighter in March than in January (Fig. 3), this light intensity , will be reached later in the day as the season progresses, resulting in hens going to roost later and later. Furthermore, since a certain length of time is required to achieve final roosting (the 'settling period'), the light intensity will decline more rapidly over this settling period as the season progresses, resulting in hens ground-roosting at decreasing lux levels (line \# in Fig. 5).
In conclusion, our data show that there is a consistent lag of $\approx 35 \mathrm{~min}$ between the time that the evening light intensity reaches 14976 lux, and the time that the hens finally go to roost. These data support the model presented in Fig. 5, in which the cue for the initiation of roosting is a particular light intensity, constant over the season. It may be possible that light intensity is not the primary causal factor, but is temporally related to some alternative, unknown variable. However, we believe that our multivariate analysis has accounted for all the most likely environmental variables and thus conclude that light intensity is the strongest candidate for the stimulus to initiate roosting. Nevertheless, additional evidence may be provided by further studies, observing hens in the hour prior to roosting, and paying particular attention to their behaviour at 14976 lux. 


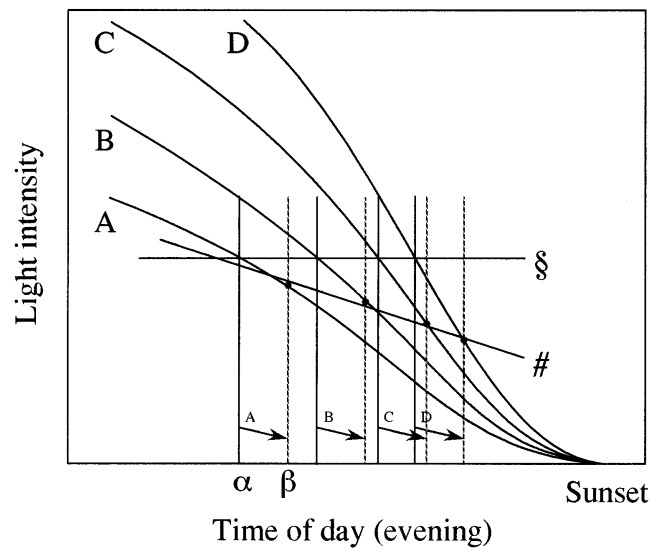

Fig. 5. Model showing changes in light intensity approaching sunset on different dates. Lines A, B, C, D and \# are as described in Fig. 3. The model predicts that females make the decision to go to roost at a certain lux level (§), which is constant over the season. This decision is made at time $\alpha$, which occurs earlier in the day on date (A) than on date (D). It is suggested that the ground-roosting process takes several minutes (until time $\beta$ ), by which time light intensity will have declined. Light intensity declines more rapidly later in the season, resulting in hens roosting at later times and lower light levels as the season progresses.

\section{Acknowledgements}

We wish to thank APSO (The Agency for Personal Services Overseas) for financial assistance via the graduate research exchange programme (A. McE) and to ASAB (Association for the Study of Animal Behaviour) for a small project grant (HVB) and to Marcel Badji, David Connors and Fr. Philip Crow for providing facilities; Bakari Gattah and Dómhnall Jennings for technical assistance; the many householders in Bwiam for allowing access to their fowl; and Dr Adrian Dunne, University College Dublin, for statistical advice.

\section{References}

Applin, D.G. and Cloudsley-Thompson, J.L., 1982. Biological Periodicities: a new interpretation. Meadowfields, Shildon.
Bhatti, B.M. and Morris, T.R., 1978a. Entrainment of oviposition in the fowl using light-dark cycles. Br. Poult. Sci., 19: $333-340$.

Bhatti, B.M. and Morris, T.R., 1978b. The relative importance of sunrise and sunset for entrainment of oviposition in the fowl. Br. Poult. Sci., 19: 365-371.

Brady, J., 1979. Biological Clocks. Edward Arnold, London, UK.

Brady, J. (Editor), 1982. Biological Timekeeping. Cambridge University Press, Cambridge.

Brückner, G.H., 1933. Untersuchungen zur Tiersoziologie inbesondere zur Auflösung der Familie. Zeit. Psychol., 128: $1-105$.

Davis, D.E., 1955. Population changes in roosting time of starlings. Ecology, 36: 424-430.

Davis, G.J. and Lussenhop, J.F., 1970. Roosting of starlings (Sturnus vulgaris): a function of light and time. Anim. Behav., 18: 362-365

Gwinner, E., 1975. Circadian and circannual rhythms in birds. In: D.S. Farner, J.R. King and K.C. Parkes (Editors), Avian Biology Vol. 5. Academic Press, New York, pp. 221-285.

Hader, D.-P. and Tevini, M., 1987. General Photobiology. Pergamon Press, Oxford.

Kent, J.P., 1992. Maternal aggression and inter-individual distance in the broody hen (Gallus gallus). Behav. Process., 27: $37-44$.

Kleinbaum, D.G., Kupper, L.L. and Muller, K.E., 1988. Applied Regression Analysis and Other Multivariate Methods (2nd Edition). PWS-Kent Publishing Company, Boston, MA.

McBride, G., Parer, I.P. and Foenander, F., 1969. Social organisation and behaviour of the feral domestic fowl. Anim. Behav. Monogr., 2: 127-181.

Morris, T.R., 1973. The effects of ahemeral light and dark cycles on egg production in the fowl. Poult. Sci., 52: 423-445.

Palmer, J.D., 1976. An Introduction to Biological Rhythms. Academic Press, NY.

Petherick, J.C. and Waddington, D., 1991. Can domestic fowl (Gallus gallus domesticus) anticipate a period of food deprivation? Appl. Anim. Behav. Sci., 32: 219-226.

Pittendrigh, C.S., 1972. Circadian surfaces and the diversity of organisation in photoperiodic clocks. Proc. Natl. Acad. Sci. 69: 2734-2737.

Pittendrigh, C.S. and Minis, D.H., 1964. The entrainment of circadian oscillations by light and their role as photoperiodic clocks. Am. Nat., September: 261-294.

Reebs, S.G., 1986. Influence of temperature and other factors on the daily roosting times of black-billed magpies. Can. J. Zool., 64: 1614-1619.

Reebs, S.G., 1994. The anticipation of night by fry-retrieving convict cichlids. Anim. Behav., 48: 89-95.

Saunders, D.S., 1977. An Introduction to Biological Rhythms. Blacktie, Glasgow.

Siegel, S., 1956. Nonparametric Statistics for the Behavioural Sciences. McGraw-Hill, N.Y. 
Swingland, J.R., 1976. The influence of light intensity on the roosting times of the rook (Corvus frugilegus). Anim. Behav., 24: 154-158.

Wood-Gush, D.G.M., Duncan, I.J.H. and Savory, C.J., 1978. Observations on the social behaviour of domestic fowl in the wild. Biol. Behav., 3: 193-205.
Workmann, L. and Andrew R.J., 1989. Simultaneous changes in behaviour and in lateralisation during the development of male and female domestic chicks. Anim. Behav., 38: $596-605$.

Zar, J.H., 1984. Biostatistical Analysis (2nd Edition). PrenticeHall, Englewood Cliffs, NJ. 